\title{
Laboreal
}

Volume $16 \mathrm{~N}^{\circ} 2$ | 2020

Programa de Pesquisa do Curso da Ação

\section{0 : Pandemia por Covid-19 y mundo del trabajo : una mirada desde los sectores subalternos}

2020: a Pandemia da Covid-19 e o mundo do trabalho: um olhar a partir dos setores marginalizados

Jairo Ernesto Luna-García y Mauricio Torres-Tovar

\section{OpenEdition}

Journals

Edición electrónica

URL: http://journals.openedition.org/laboreal/17427

DOI: $10.4000 /$ laboreal. 17427

ISSN: 1646-5237

Editor

Universidade do Porto

Referencia electrónica

Jairo Ernesto Luna-García y Mauricio Torres-Tovar, « 2020 : Pandemia por Covid-19 y mundo del

trabajo : una mirada desde los sectores subalternos », Laboreal [En línea], Volume 16 N² | 2020,

Publicado el 01 diciembre 2020, consultado el 14 diciembre 2020. URL : http://

journals.openedition.org/laboreal/17427 ; DOI : https://doi.org/10.4000/laboreal.17427

Este documento fue generado automáticamente el 14 diciembre 2020.

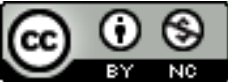

Laboreal está licenciado com uma Licença Creative Commons - Atribuição-NãoComercial 4.0 Internacional. 


\title{
2020 : Pandemia por Covid-19 y mundo del trabajo : una mirada desde los sectores subalternos
}

\author{
2020 : a Pandemia da Covid-19 e o mundo do trabalho: um olhar a partir dos \\ setores marginalizados
}

Jairo Ernesto Luna-García y Mauricio Torres-Tovar

1 Luego de un ciclo de conferencias con ponentes de diversas regiones del planeta [1], que abordaron como tema central la situación de salud de los y las trabajadoras en tiempos de pandemia, caben algunas reflexiones en relación con el impacto que la pandemia por la covid-19 en el mundo del trabajo, y la respuesta que desde las organizaciones sindicales se viene dando a esta situación.

\section{Una experiencia global : no todos atraviesan la tormenta en el mismo barco}

2 Un primer elemento que cabe destacar es la rápida difusión que ha tenido esta pandemia y el amplio grado de afectación de territorios y poblaciones, colocándose como una experiencia compartida prácticamente por el conjunto de miembros de la especie humana.

3 Sin embargo, los diferentes grupos sociales no experimentamos de la misma manera la actual situación, con grandes diferencias en el Norte Global con respecto al Sur Global. Si bien la manifestación de la pandemia expresa en un primer momento las centralidades y vínculos internacionales, colocando como portadores activos a aquellos sectores más vinculados con la movilidad internacional (especialmente aérea), grupo en que hay mayor representación de élites, una vez se instala la pandemia en los territorios, son los sectores subordinados los que reciben las peores afectaciones.

De esta forma, la pandemia desnuda las inequidades resultantes de la división internacional del trabajo, pero también derivadas de las estructuras clasistas, sexistas y 
racistas, que devienen en que la mayor mortalidad sea en personas de los sectores empobrecidos tanto en el Norte como del Sur del planeta, aunque con mayor severidad en este último.

\section{La pandemia y el mundo del trabajo : la tecnología y las inequidades que se profundizan}

5 Si bien se sostiene que la acción frente a la pandemia ha sido desigual en los diferentes países, y que hubo una actitud de negación entre empresarios y gobiernos que incidieron en el retraso en las medidas de intervención, presentando mayor severidad la problemática en algunos de ellos, existe una gran similitud en el tipo de respuestas ante la situación. Especialmente en los periodos de cuarentena, la segmentación de la población trabajadora de acuerdo con sus condiciones de empleo y su factibilidad de adecuar la actividad laboral al uso de la tecnología de la información y comunicación (trabajo a distancia), muestra condiciones muy distintas :

6 En primer lugar, en el Sur Global amplios grupos de trabajadores y trabajadoras en la economía informal se vieron enfrentados al dilema de acogerse a las medidas de aislamiento y verse sometidos a condiciones de hambre, ante la ausencia o limitada cobertura de programas de protección social que les garantizara solventar sus necesidades en el encierro.

7 En segundo lugar, quienes se encuentran en condiciones de empleo formal fueron clasificados en ámbitos de trabajadores esenciales y no esenciales, a pesar del llamado de un grupo de expertos de Naciones Unidas a considerar a todos como trabajadores esenciales reconociendo la importancia del trabajo para la existencia de la sociedad. Las medidas de protección para aquellos que continuaron laborando en medio de la cuarentena varían ostensiblemente entre Norte y el Sur Global. De igual forma, el retorno al trabajo de aquellos considerados no esenciales, luego del relajamiento de las medidas de encierro, también tiene condiciones muy disímiles en las dos regiones, siempre en desmedro de aquellos que viven en la región con mayores niveles de explotación en el planeta.

8 En tercer lugar, una proporción importante de las actividades laborales en el planeta se sumió en este periodo en el trabajo a distancia o desde el hogar, afectando de manera ostensible la relación trabajo - familia. Los estudios que se han llevado a cabo en algunos países hacen referencia a fenómenos de extensión e intensificación de las actividades laborales, frecuentemente sin que se haya presentada la adecuación de puestos de trabajo, ni el suministro de elementos por parte de los empleadores. Aquí también los recursos con que cuentan las y los trabajadores, manifiestan las diferencias en condiciones de vida entre regiones, países, zonas urbanas y rurales y clases sociales, y las inequidades se ven a su vez incrementadas por las demandas derivadas del cierre de los espacios educativos y de cuidado, con lo cual se genera sobrecarga especialmente para las mujeres.

9 Finalmente, se puso en evidencia la existencia de una gran masa de población en buena medida prescindible para el funcionamiento de la economía capitalista, aquellos ubicados en las condiciones más precarias que desarrollan actividades presenciales no esenciales, donde se generalizó el desempleo y la drástica disminución de ingresos. Para este grupo la pandemia ha tenido los mayores costos en sufrimiento y pérdida de vidas 
y muestra lo poco eficaces que han sido los llamados vacuos a la solidaridad internacional y el gran desprecio del capital por aquellos que no le son rentables. La expresión de algunos pocos estallidos sociales no se compadece con la gravedad de la situación.

\section{La respuesta de la fuerza laboral : el papel de los sindicatos}

10 La crisis que acompaña la actual situación ha tenido una respuesta notable desde los sindicatos, dependiendo de la fuerza que ellos tienen en las diferentes regiones y actividades económicas. Para el caso de Europa, se menciona que en lo recorrido del presente año hay una importante reivindicación frente a la garantía de la protección de la salud frente a la pandemia, poniendo de presente un debate en relación con la organización del trabajo que confronta la perspectiva higienista que omite las implicaciones de la bioseguridad en diferentes contextos laborales [2].

11 En Estados Unidos, este periodo se acompañó de la presencia de un movimiento huelguístico reivindicando mayores garantías laborales y la protección frente a los riesgos de llevar adelante las actividades laborales en el marco de la pandemia, acompañado de la búsqueda de un mejor reconocimiento económico para la población trabajadora perteneciente al grupo de actividades esenciales [ $\left.{ }^{3}\right]$.

12 En el Sur Global la incidencia de los sindicatos es menor, debido a importantes restricciones en el ejercicio de la libertad sindical pero también por el menor peso del empleo formal. Aquí vale la pena resaltar la acción de sindicatos que agrupan a trabajadoras y trabajadores de la salud, quienes previamente venían sufriendo la precarización de sus condiciones de empleo y trabajo, y sobre quienes recayó un importante papel para enfrentar la crisis de la pandemia. La acción impulsada por la Internacional de los Servicios Públicos (ISP) [4], permitió estimular y coordinar esfuerzos frente a la garantía de protección de este importante grupo, pero también confrontar las pésimas condiciones de empleo en que llevan adelante su trabajo. También se destacan, algunos ejercicios hechos por los propios sindicatos de profesionales de la salud, para monitorear las condiciones laborales, de bioprotección, de contagio y muerte por covid-19 de trabajadores del sector salud, buscando denunciar y exigir a los gobiernos actuar para proteger la vida de quienes están en la primera línea de atención a la pandemia.

\section{El covid 19 como enfermedad o accidente laboral}

13 Otra dimensión expuesta por la crisis ha sido la diversidad de modelos de protección social alrededor del planeta, y por ende grandes diferencias en cuanto a las coberturas para garantizar prestaciones asistenciales y económicas con ocasión de ser contagiado por Sars-Cov-2 en el trabajo.

14 En una parte importante de los países del Norte Global, se incluyó la enfermedad por coronavirus como accidente de trabajo o enfermedad laboral, tanto para los trabajadores de la salud como para aquellos involucrados en los sectores esenciales, mientras que en los países del Sur Global la situación es muy heterogénea : desde países 
donde no se reconoció, hasta algunos en que se reconoce parcialmente solo en trabajadores de la salud y en pocos de manera amplia.

Las estadísticas permiten identificar que, para la población en edad de trabajar, se puede identificar como principal fuente de contagio la ocupación, y sin embargo las garantías de protección son significativamente distintas. Como resultado de esto, no solamente se presenta una posibilidad disímil de protegerse, sino también una probabilidad distinta de enfermar y acceder a los servicios de atención a la salud y a la cobertura de las prestaciones económicas.

\section{De inequidades en el empleo y el trabajo}

16 La actual situación ha tenido un profundo impacto en el mundo del trabajo, afectando negativamente a la mayor parte de la población trabajadora en diferentes dimensiones : pérdidas de empleo, disminución de ingresos, profundización de los problemas de salud relacionados con la organización del trabajo tanto en las actividades presenciales como aquellas que migraron hacia labores desarrolladas en casa o a distancia, profundización de las inequidades en relación con el reconocimiento del covid 19 como accidente de trabajo o enfermedad profesional, entre otras.

Mientras que para los empleadores la situación motiva solicitud de apoyo económico de los Gobiernos para proteger sus negocios y visualizan su responsabilidad en el ámbito de un renovado higienismo al colocar el énfasis en las medidas de auto bio-protección por parte de las y los trabajadores, para los sindicatos la confrontación de la situación se relaciona con superar problemas estructurales de inequidades en condiciones de empleo y trabajo, la defensa del derecho a la salud desde la organización del trabajo para una prevención profunda y la búsqueda de políticas de protección social universalistas y que garanticen plenamente los derechos.

18 Sin embargo, hay una dimensión más general de toda esta situación en relación con la presencia de beneficios importantes derivados de la pandemia para los monopolios de las tecnologías de la información y las comunicaciones, el complejo médico industrial y el sector financiero internacional que ante las necesidades de gasto social se ven favorecidos con los incrementos de las deudas públicas para atender los gastos en la emergencia.

19 A la par, otra damnificada de la situación es la protesta social que se ve restringida en el marco de las medidas de control social soportadas en la necesidad de atender la pandemia. La adopción de estados de excepción y concentración de poder en los órganos ejecutivos ha puesto de presente el importante papel del Estado, pero con un balance que no necesariamente se coloca en favor de los intereses colectivos.

\section{Colombia : espejo de la crisis laboral, sanitaria y social}

La pandemia en Colombia, como reflejo de lo que ocurre en muchas latitudes, reveló con crudeza las grandes desigualdades sociales, la precariedad del mundo del trabajo y la ausencia de políticas universales de seguridad social, con especial en lo referente a mecanismos de protección de la salud en el trabajo y de protección económica. 
21 Aunque el Gobierno Nacional tomó al inicio de la pandemia por covid-19 medidas de aislamiento general obligatorio, la ausencia de reales formas de protección social para el conjunto de la población obligó principalmente a los sectores económicos informales, que en Colombia ronda en cifras oficiales el $50 \%$ de la población laboral activa [5], a salir a buscar el sustento diario, lo que incrementó la tasa de contagio por SAR-CoV-2.

Asunto al que se sumó el desconfinamiento general 6 meses después de ingresado el virus al territorio nacional, bajo el argumento que no se podía detener más la dinámica economía porque esto podría producir más consecuencias letales que la propia pandemia ; lo que llevó a que el país se ubicara entre los primeros en el mundo en tasa de contagio y en tasa de letalidad por la covid-19.

Esta situación sin duda ha impactado principalmente a los sectores sociales subalternos de la sociedad. De un lado, los sectores pobres son los que han sufrido principalmente el contagio por el SAR-CoV-2 y los que han muerto principalmente por la covid-19. Y de otro lado, los sectores económicos de la micro y pequeñas empresas y los de la informalidad, son los que han sufrido más estragos y pérdidas, dado que el gobierno concentró las ayudas económicas en los grandes sectores empresariales y en la banca, dejando a su merced a los sectores más débiles de la economía, que llevó a que en Colombia se perdieran más de 5 millones de trabajo en estos meses de la pandemia [ $\left.{ }^{6}\right]$.

En relación con la protección de la salud en el trabajo, las medidas han sido completamente insuficientes, subordinadas a la lógica y comportamiento de las aseguradoras de riesgos laborales, quienes no asumieron un rol solidario y comprometido con la salud y la vida de los trabajadores afiliados, al sobreponer sus intereses económicos. La situación más dramática la han vivido las y los trabajadores de la salud, quienes, como primera línea de atención a la pandemia, no han laboran con estrictos protocolos de bioseguridad, lo que ha llevado a que se hayan infectado más de 17.000 trabajadores/as y hayan muerto $93\left[^{7}\right]$. De otros sectores de trabajadores esenciales, como se han denominado, no se conoce información precisa, al igual de lo que viene ocurriendo con el grueso de trabajadores informales.

El gobierno nacional tratando de contrarrestar esta dramática situación de los trabajadores del sector de la salud, que es reflejo de años de precariedad laboral impuesta por un sistema de salud que se ha ido privatizando paulatinamente desde su implementación a través de la Ley 100 de 1993, lo que ha hecho es declarar la covid-19 como enfermedad laboral, pero solo para los trabajadores de la primera línea de atención a la pandemia y darles una indemnización económica. Claramente una política que busca cambiar salud por dinero y que no afecta los problemas estructurales que explican el grave impacto de la pandemia sobre este sector de trabajadores.

Por último, es de mencionar, que a pesar de las restricciones de agrupación y movilización que impuso la pandemia, se han dado expresiones de protesta y lucha en este periodo, denunciando la situación y exigiendo cambios de fondo. En particular las y los trabajadores de la salud han generado multitud de acciones colectivas, incluido huelgas y han reactivado y renovado formas organizativas, exigiendo trabajo digno, estable y en condiciones seguras para la salud.

De manera general el movimiento sindical en Colombia, aunque no se ha paralizado, ni se ha quedado callado, su capacidad de movilización e incidencia en este periodo se ha visto muy mermada, con lo cual poco ha podido incidir en la orientación de las medidas 
de salud pública y de protecciones sociales que se deben dar para enfrentar adecuadamente la pandemia.

\section{No volver a la normalidad porque era el problema}

De esta forma, hay un espectro amplio de implicaciones de la pandemia en el mundo del trabajo, en detrimento de los trabajadores y trabajadoras, que se expresa de manera inequitativa en las regiones, entre países, con respecto a las ciudades y las áreas rurales, entre los sexos y grupos étnico-raciales que llaman a poner en evidencia la actual situación y a estimular el apoyo a los procesos de defensa de los derechos colectivos, a la par de buscar un cambio en las políticas de protección social encaminado a una universalización de los derechos.

En este marco, no es posible hablar de volver a la normalidad entendiendo que la situación previa es la que permite explicar la actual crisis, pero el escenario de pospandemia requiere un replanteamiento de prioridades hacia una reconfiguración de fuerzas que permita apostar por un futuro donde se revise en profundidad la dirección hacia donde van nuestras sociedades, que supere el actúa mundo del trabajo tóxico en que estamos, recuperando el lugar central del trabajo, pero que a la vez recomponga la esencia humana del trabajo como escenario de crecimiento y emancipación, y valore la importancia de la población que produce los verdaderos valores en la sociedad, para que realmente haya un compromiso hacia la vida y la salud de trabajadores y trabajadoras alrededor del planeta. Este es el reto para personas, organizaciones y sectores progresistas, para hacer una solidaridad eficaz, que a la vez es para con nuestro propio futuro como especie.

\section{NOTAS}

1. Se efectuaron siete sesiones en que participaron 27 ponentes de Europa, América del Norte, Centro América y el Caribe, Región Andina, Cono Sur, África del Sur y Sur de Asia. Las grabaciones están disponibles en https://www.youtube.com/channel/ UC6Uhp4i0929UJDOPKat20kg/videos

2. Ver, por ejemplo, https://www.etui.org/publications/essential-unprotected-highly-mobileworkers-eu-during-covid-19-pandemic

3. www.coshnetwork.org/coronavirus

4. https://publicservices.international/resources/news/covid-19-emergency--psi-prioritiesandperspectives $?$ id $=10694 \&$ lang $=$ en

5. Ver: www.dane.gov.co/index.php/estadisticas-por-tema/mercado-laboral/empleo-informaly-seguridad-social

6. https://www.semana.com/nacion/articulo/coronavirus-en-colombia-54-millones-depersonas-perdieron-el-trabajo-en-abril/675140/

7. http://www.ins.gov.co/Noticias/Paginas/coronavirus-personal-salud.aspx 


\section{AUTORES}

\section{JAIRO ERNESTO LUNA-GARCÍA}

Universidad Nacional de Colombia, Grupo Salud Ambiental y Laboral - Doctorado Interfacultades en Salud Pública, Cra 45, Bogotá, Colômbia

jelunag@unal.edu.co

\section{MAURICIO TORRES-TOVAR}

Universidad Nacional de Colombia, Grupo Salud Ambiental y Laboral - Doctorado Interfacultades en Salud Pública, Cra 45, Bogotá, Colômbia

mhtorrest@unal.edu.co 